\title{
Impact of Lycopene intervention on serum homocysteine in patients of Myocardial Infarction
}

\author{
Chauhan AP', Shah $\mathbf{P K}^{2}$ \\ ${ }^{1}$ Dr. Asutosh P Chauhan, Associate Professor, Department of Biochemistry, ${ }^{2}$ Dr. Pankil K Shah, Assistant Professor, \\ Department of Biochemistry. Both are affiliated with GMERS Medical College, Gotri, Vadodara, Gujarat, India
}

Address for correspondence: Dr. Asutosh P Chauhan, Email: dr.ashutoshchauhan@gmail.com

\begin{abstract}
Introduction: Myocardial Infarction occurs due to any obstruction in coronary arteries leading to ischemia followed by infarction. It is characterized by systemic inflammation, elevated levels of inflammatory cytokines and atherosclerotic plaques. Plaque formation and Inflammation are significant contributor in the pathophysiology of MI. Antioxidants slow the progression of MI because of their ability to inhibit inflammatory processes. The aim of this study was to test an intervention in patients with MI to assess the effect of dietary lycopene on one of the independent risk factor for MI i. e Serum Homocysteine. Methods: Sixty participants with MI were randomly assigned to two groups: with lycopene intervention and without intervention. The intervention group received $27.212 \mathrm{mg}$ of lycopene per day by drinking 1 serve (approx. 243 grams) of tomato soup for 90 days. Serum lycopene, and Serum Homocysteine were measured. Results: Plasma lycopene levels increased in the intervention group as compared with the non intervention group ( 0.50 $\mu \mathrm{mol} / \mathrm{L}$ to $0.75 \mu \mathrm{mol} / \mathrm{L}, \mathrm{P}=.002 ; 0.55 \mu \mathrm{mol} / \mathrm{L}$ to $0.57 \mu \mathrm{mol} / \mathrm{L})$. Mean serum Homocysteine levels decreased significantly in the intervention group. The mean serum Homocysteine in pre intervention group was $29.77 \mu \mathrm{mol} / \mathrm{L}$ with S.D of $6.97 \mu \mathrm{mol} / \mathrm{L}$ and in post intervention subjects was $11 \mu \mathrm{mol} / \mathrm{L}$ with S.D of $1.96 \mu \mathrm{mol} / \mathrm{L}$ with a palue of 0.0001 which is statistically significant. Conclusions: These findings show that the antioxidant Lycopene in a 90 -day intervention of tomato soup significantly decreases S. Hcy (Homocysteine) levels in a sample of patients with MI.
\end{abstract}

Key words: Myocardial Infarction, S. Homocysteine, Lycopene, Antioxidant

\section{Introduction}

Inspite of enough progress that has been made in the preventing and curing of cardiovascular disease (CVD), it remains the primary cause of mortality throughout the western countries and the second most common cause worldwide[1]. By the coming few years, it is estimated that nearly $40-45 \%$ of all deaths worldwide will be due to $\mathrm{MI}$, more than twice the percentage of deaths from cancer.

Myocardial Infarction is commonly a result of ischemic heart disease or hypertension. Inflammation plays a role in stages of atherosclerosis and thrombosis, the underlying cause of approximately $80 \%$ of all sudden cardiac death (SCD). The relation between increased intake of antioxidants and reduced cardiovascular

Manuscript received: $9^{\text {th }}$ Nov 2015

Reviewed: $17^{\text {th }}$ Nov 2015

Author Corrected: $30^{\text {th }}$ Nov 2015

Accepted for Publication: 19 $19^{\text {th }}$ Dec 2015 disease (CVD) risk has been demonstrated in different epidemiological and observational studies [2-5]. Heart failure has a major inflammatory component, and MI is the most common cause of HF [6]. The connection between inflammatory pathways and disease progression of MI has been supported by studies pointing out that increased plasma cytokine levels seen in patients in various stages of HF [7].

The oxidative stress generates specifically in mitochondria from reactive oxygen species and reactive nitrogen species (ROS/RNS) and can be observed in many of the key steps in the pathophysiological mechanism of atherosclerosis and the consequential clinical manifestations of cardiovascular disease. Besides formation of atherosclerosis, it involves lipid metabolism abnormality, plaque breakdown, thrombus formation, myocardial injury, cell death, fibrosis and heart failure. The identification of the critical importance of oxidative stress has led to the profound 
use of antioxidants in the treatment and prevention of heart disease [8]. Role of antioxidants in reducing the inflammatory process have been indicated [9-11]. Reactive oxygen and nitrogen species in high levels in the plasma is thought to be one of the contributing factors to MI because of the oxidation of lipids and damage to the endothelium of the vasculature [12-15]. Increased levels of reactive oxygen species in the myocardial muscles can be caused by elevated inflammatory cytokines or by a disruption of antioxidant production. Elevated antioxidant plasma levels established in relation with intake of vegetables and fruits have been found both to be inversely related to MI cases and to demonstrate a decreased risk of events connected to HF $[16,17]$. Lycopene is a superior antioxidant found in all type of food products and is considered to be one of the most efficient antioxidant at reducing reactive oxygen species, also known as free radicals $[18,19]$. Oxidative stress occurs when there is imbalance between free radicals and endogenous antioxidants [14]. Given the role of inflammation in MI, a novel strategy increased intake of dietary lycopene can help in preventing the complications of HF.

Homocysteine, a sulphur containing amino acid was first mentioned in 1931 by Vigneaud. Increased plasma levels of Homocysteine have been associated with vascular disease. The hallmarks of homocystinuria [20] are Marfanoid appearance, Ectopic lentis, vascular manifestations, nervous and Musculo- skeletal manifestations. In serum only about $1 \%$ of total Homocysteine is found in free reduced form. The major part of Homocysteine in blood is in oxidized form and either is bound covalently to the proteins or exists in disulfide form. The determinants of total Homocysteine in serum includes several genetic defects in enzymes especially cystathionine beta synthase and MTHFR polymorphism [21, 22], diabetes, age and gender, steroid hormones, drugs, vitamin status, thyroid disease etc. Homocysteine has been known to cause vascular injury by multiple number of mechanisms:Homocysteine promotes leukocyte recruitment by up regulating monocyte chemoattractant protein -I as well as interleukin-8 expression and secretion [23]. It also leads to LDL oxidation which has peroxidation effect on lipids. Homocysteine increases smooth muscle cell proliferation and increases collagen production [24]. And it also causes endothelial injury directly. Prothrombotic effects of Homocysteine, which have been demonstrated in patients with acute coronary diseases and stroke, include attenuation of endothelial tissue plasminogen activator binding sites, activation of factors especially VIIa and V, inhibition of protein C and heparin sulphate, elevated fibrinopeptide $\mathrm{A}$ and prothrombin fragments 1 and 2 , increased blood viscosity, and decreased endothelial antithrombotic activity due to changes in thrombomodulin functions. Also prolonged exposure of endothelial cells to Homocysteine decreases the activity of the enzyme dimethylarginine dimethylaminohydrolase (DMDA), responsible for degrading asymmetric dimethylarginine, an endogenous inhibitor of enzyme nitric oxide synthase; this hampers the production of nitric oxide. This may contribute to impaired endothelium dependent vasodilatation of vessels. Several studies $[25,26]$ have showed that's there is a crystal clear dose-response relation between Homocysteine concentrations and cardiovascular deaths in patients with confirmed coronary diseases. Normal Homocysteine concentrations range between 5 and $15 \mu \mathrm{mol} / \mathrm{L}$ whereas hyperhomocysteinemia has been described as follows; moderate- 15 - $30 \mu \mathrm{mol} / \mathrm{L}$, intermediate- 30 $100 \mu \mathrm{mol} / \mathrm{L}$, and severe- more than $100 \mu \mathrm{mol} / \mathrm{L}$.

Thus, the purpose of this randomized controlled study was to test the effect of an intervention of a lycopene present in food product on biomarkers of inflammation in patients with MI. Our first objective was to compare the serum levels of S. Homocysteine (Hcy) in 2 groups of patients with MI. The first group (intervention) consumed 1 serving of tomato soup, daily and was compared with a second group (control) of HF patients who did not consume tomato soup daily. Second objective was to see the impact of lycopene on S. Hcy level in MI patients.

\section{Materials and Methods}

The Study Population: The study population consisted of 60 patients having Acute Myocardial Infarction and diagnosed by clinical symptoms and signs, Electrocardiogram and cardiac markers like CK-MB. They were randomly divided into two groups either an intervention group $(n=40)$ or a control group $(n=20)$. The intervention group was given one serving (243 gms) of fresh tomato soup to drink each day for 90 days while consuming their normal diet. The control group continued to consume their normal diet and no tomato soup was given to them. Data collection included clinical information, random 24-hour dietary food recalls, and blood samples for levels of S.Hcy, and lycopene. 
Inclusion criteria for patients in this study included- (1) Severe chest pain lasting for $>30$ minutes and not responding to sublingual nitroglycerine tablets significantly. (2) Presence of abnormal Q wave with ST segment elevation and subsequent $\mathrm{T}$ wave inversion appearing in anterior, inferior or right leads corresponding to anterior wall, inferior wall and right wall myocardial infarction respectively. (3) Significant rise in CK-MB isoenzyme on 1 st or 2 nd day.

Sample collection and preparation: Plasma lycopene was obtained into purple EDTA vacutainer tubes from venous blood (approximately $5 \mathrm{~mL}$ ) that was drawn via needle and syringe from the forearm. Serum Homocysteine levels was measured in a 12 hour fasting blood sample. $5 \mathrm{ml}$ of blood was drawn and collected in a plain vacutte for the estimation of Homocysteine and Lipid profile. $2 \mathrm{ml}$ of blood was collected in Fluoride vacutte for blood glucose estimation. Approx. 10 hours of fasting prior to sample collection is required. Plasma or serum is preferred. Collected Blood should be centrifuged within 30 minutes or kept on ice until centrifugation.

Measurement: For Lycopene estimation Plasma was immediately separated from red blood cells by centrifuging at for 10 minutes. Blood plasma was then placed into vials and stored at $-80 \mathrm{C}$ and sent to laboratory with facility of lycopene estimation where extraction and HPLC-Photo diode array analysis was carried out. S. Homocysteine- Serum Homocysteine was measured by FPIA (Fluorescence Polarization Immunoassay) technique by AxSYM Assay system using the principle of conversion of oxidized Homocysteine to reduced form and then converting into S-adenosyl-L-Homocysteine (SAH).

\section{Results}

A total of 60 patients were selected. All of the patients had Myocardial Infarction. There were no significant differences between patients with respect to age, gender, body mass index (BMI), MI etiology, NYHA classification, medications, and smoking history or exercise patterns. All patients who enrolled in the study completed the study.

Statistical Analysis

All data analyses were conducted, and a $\mathrm{P}$ value of $<0.05$ was considered statistically significant. To compare baseline differences between the 2 treatment groups, paired and unpaired t tests were used.

Serum Lycopene levels increased significantly in intervention group as compared to control group.

Table-I: Serum Lycopene in control and interventional group

\begin{tabular}{|l|l|l|}
\hline S. Lycopene & Control group & Intervention group \\
\hline At start the study & $0.55 \mu \mathrm{mol} / \mathrm{L}$ & $0.50 \mu \mathrm{mol} / \mathrm{L}$ \\
\hline After the study ( 30 days after) & $0.57 \mu \mathrm{mol} / \mathrm{L}$ & $0.75 \mu \mathrm{mol} / \mathrm{L}$ \\
\hline
\end{tabular}

P value -0.002 .

S. Hcy- Serum level of Homocysteine considerably decreased in all the intervention subjects irrespective of gender.

Table - II: Serum Hcy in pre intervention and Post intervention group-

\begin{tabular}{|l|l|l|}
\hline S. Hcy & Pre intervention & Post intervention \\
\hline Mean & $29.77 \mu \mathrm{mol} / \mathrm{L}$ & $11.00 \mu \mathrm{mol} / \mathrm{L}$ \\
\hline S.D & $6.97 \mu \mathrm{mol} / \mathrm{L}$ & $1.96 \mu \mathrm{mol} / \mathrm{L}$ \\
\hline
\end{tabular}

p value $-<0.0001$

\section{Discussion}

Elevated levels of Homocysteine seem to be clearly related to an inflated risk of cardiovascular disease. JAMA 2002 reports an analysis [27] in that evaluated information from thirty prospective and retrospective studies. This can be the study during which an intervention of a lycopene-rich food supply has been tested in a sample of patients with MI. To date, there are different studies within which the role of 
antioxidants in patients with HF has been studied. In those studies, there was a positive association between plasma carotenoid levels and HF; each of those studies were data-based [28,29]. In our study, we tend to found a major impact of lycopene intervention on the levels of S. Hcy, a possible inflammatory marker. lycopene levels accrued considerably within the intervention cluster over time, whereas remaining unchanged within the control cluster. Levels of inflammatory markers in weighty persons are thought-about freelance predictors of MI. Higher waist-to-hip quantitative relation (WHR) and bigger waist circumference are found to be independently related to a considerably inflated age adjusted risk of MI and HF [30-32]. within the Nurses' Health Study, ladies with a WHR of 0.88 or higher had a relative risk of 3.25 (95\% confidence interval, 1.785.95) for CVD compared with ladies with a WHR of less than 0.72.30. There was no gender distinction in BMI level in our sample of patients. there's ample proof to support that S.Hcy causes smooth muscle proliferation, enhances collagen production and causes direct epithelium injury[33] the actual fact that our study found that S.Hcy levels attenuate in response to a dietary intervention may be a positive finding. If S.HCY levels are raised in patients with MI, they'll additional increase with the severity of the pathology and be related to a higher rate of mortality. Our information conjointly indicates that augmented consumption of lycopene-containing food product leads to raised plasma levels of lycopene. These data support previous studies where accrued dietary intake of lycopene is mirrored in augmented circulating lycopene levels in plasma [34-36] Compliance to the tomato soup intervention was ascertained in our study. Processed foods containing high levels of lycopene conjointly contain high levels of sodium and high sodium intake is an freelance risk factor for HF exacerbation [37-39] we cannot attribute the intervention impact exclusively to lycopene, as tomato soup will contain a spread of antioxidants and vitamins in little amounts. However, it does contain an outsized quantity of lycopene. With reference to the practicableness of this study of a dietary intervention, we found that patients with MI were able to adhere to the intervention, as proved by a compliance rate of 100 percent. The patients didn't report any sick effects from drinking the lycopene product for ninety days. This intervention was simply enforced by a sample of patients with troublesome selfcare regimens. Additionally to establishing practicableness, the study has strength within the 2group randomization of participants. There are many limitations to the current study due to the little sample size, it's tough to generalize to the complete population of individuals with MI. further biomarkers of inflammation, like inflammatory cytokines, may be measured in conjunction with S.HCY to more elucidate the impact of inflammation in MI.

\section{Conclusion}

The study of the effect of antioxidants in diet as interventions for inflammation in patients with MI is novel. Lycopene is a naturally occurring compound found in many vegetables \& fruits. Lycopene containing merchandise are cheap, promptly obtainable. In a sample of patients with MI who received a lycopene-rich dietary product, we found a major increase in plasma lycopene levels. Serum S.HCY levels, as a biomarker of inflammation, did decrease within the intervention cluster as an entire. These findings recommend that the present antioxidant lycopene interacts to have an effect on S.HCY levels in a sample of patients with MI. though a physiological mechanism is unclear, further studies can facilitate clarify this finding. This study provides insight to the potential role of antioxidants, like lycopene, in MI and should result in further treatment methods. These findings are a preliminary step in a method of building efficaciousness of a particular dietary intervention with antioxidants that will have a clinically vital impact on inflammation in patients with MI.

\section{Funding:Nil. Conflict of interest: Nil. Permission for IRB: Yes}

\section{References}

1. Blecker S, Paul M, Taksler G, Ogedegbe G, Katz S. Heart failure-associated hospitalizations in the United States. J Am Coll Cardiol. 2013 Mar 26;61(12):125967.

2. Hak AE, Stampfer MJ, Campos H, Sesso HD, Gaziano JM, Willett W, Ma J. Plasma carotenoids and tocopherols and risk of myocardial infarction in a low-risk population of US male physicians. Circulation. 2003 Aug 19;108(7):802-7. Epub 2003 Aug 4.

3. Sesso HD, Buring JE, Norkus EP, Gaziano JM. Plasma lycopene, other carotenoids, and retinol and the risk of cardiovascular disease in women. Am J Clin Nutr. 2004 Jan;79(1):47-53. 
4. Rao AV, Agarwal S. Role of antioxidant lycopene in cancer and heart disease. J Am Coll Nutr. 2000 Oct;19(5):563-9.

5. Klipstein-Grobusch K, Launer LJ, Geleijnse JM, Boeing H, Hofman A, Witteman JC. Serum carotenoids and atherosclerosis. The Rotterdam Study. Atherosclerosis. 2000 Jan;148(1):49-56.

6. Heymans S, Hirsch E, Anker SD, Aukrust P, Balligand JL, Cohen-Tervaert JW, Drexler H, Filippatos G, Felix SB, Gullestad L, Hilfiker-Kleiner D, Janssens S,Latini R, Neubauer G, Paulus WJ, Pieske B, Ponikowski P, Schroen B, Schultheiss HP, Tschöpe C, Van Bilsen M, Zannad F, McMurray J, Shah AM. Inflammation as a therapeutic target in heart failure? A scientific statement from the Translational Research Committee of the Heart Failure Association of the European Society of Cardiology. Eur J Heart Fail. 2009 Feb;11(2):119-29. doi: 10.1093/eurjhf/hfn043.

7. Mann DL. Targeted anticytokine therapy and the failing heart. Am J Cardiol. 2005 Jun 6;95(11A):9C$16 \mathrm{C}$; discussion 38C-40C.

8. Pashkow FJ. Oxidative Stress and Inflammation in Heart Disease: Do Antioxidants Have a Role in Treatment and/or Prevention? Int J Inflam. 2011;2011:514623. doi: 10.4061/2011/514623. Epub 2011 Aug 11.

9. Rissanen TH, Voutilainen S, Nyyssönen K, Salonen R, Kaplan GA, Salonen JT. Serum lycopene concentrations and carotid atherosclerosis: the Kuopio Ischaemic Heart Disease Risk FactorStudy.

10. Mak S, Newton GE. The oxidative stress hypothesis of congestive heart failure: radical thoughts. Chest. 2001 Dec;120(6):2035-46.

11. Ferrari R, Guardigli G, Mele D, Percoco GF, Ceconi C, Curello S. Oxidative stress during myocardial ischaemia and heart failure. Curr Pharm Des. 2004;10(14):1699-711.

12. Thomson MJ, Puntmann V, Kaski JC. Atherosclerosis and oxidant stress: the end of the road for antioxidant vitamin treatment? Cardiovasc Drugs Ther. 2007 Jun;21(3):195-210.

13. Patel RP, Moellering D, Murphy-Ullrich J, Jo H, Beckman JS, Darley-Usmar VM. Cell signaling by reactive nitrogen and oxygen species in atherosclerosis. Free Radic Biol Med. 2000 Jun 15;28(12):1780-94.

14. Trachtenberg BH, Hare JM. Biomarkers of oxidative stress in heart failure. Heart Fail Clin. 2009 Oct;5(4):561-77. doi: 10.1016/j.hfc.2009.04.003.

15. Valko M, Leibfritz D, Moncol J, Cronin MT, Mazur M, Telser J. Free radicals and antioxidants in normal physiological functions and human disease. Int $\mathbf{J}$ Biochem Cell Biol. 2007;39:44-84.

16. Levitan EB, Wolk A, Mittleman MA. Relation of consistency with the dietary approaches to stop hypertension diet and incidence of heart failure inmen aged 45 to 79 years. Am J Cardiol. 2009 Nov 15;104(10):1416-20. doi: 10.1016/j.amjcard.2009.06.061. Epub 2009 Sep 25.

17. Pfister R, Sharp SJ, Luben R, Wareham NJ, Khaw KT. Plasma vitamin C predicts incident heart failure in men and women in European Prospective Investigation into Cancer and Nutrition-Norfolk prospective study. Am Heart J. 2011 Aug;162(2):246-53. doi: 10.1016/j.ahj.2011.05.007. Epub 2011 Jul 7.

18. Arab L, Steck S. Lycopene and cardiovascular disease. Am J Clin Nutr. 2000 Jun;71(6 Suppl):1691S$5 \mathrm{~S}$; discussion $1696 \mathrm{~S}-7 \mathrm{~S}$.

19. Kohlmeier L, Hastings SB. Epidemiologic evidence of a role of carotenoids in cardiovascular disease prevention. Am J Clin Nutr. 1995 Dec;62(6 Suppl):1370S-1376S.

20. Harrison's principles of internal medicine, 17th edition. United States of America :The McGraw-Hill Companies.2007-08.

21. Folsom AR, Nieto FJ, McGovern PG, et al: Prospective study of coronary heart disease incidence in relation to fasting total homocysteine, related genetic polymorphisms, and B vitamins: The Atherosclerosis Risk in Communities (ARIC) study. Circulation 98:204-210, 1998

22. Brattström L, Wilcken DE, Ohrvik J, Brudin L. Common methylenetetrahydrofolate reductase gene mutation leads to hyperhomocysteinemia but not to vascular disease: the result of a meta-analysis. Circulation. 1998 Dec 8;98(23):2520-6.

23. Poddar, R, Sivasubramanian, N, DiBello, PM, et al. Homocysteine induces expression and secretion of 
monocyte chemoattractant protein-1 and interleukin-8 in human aortic endothelial cells: implications for vascular disease. Circulation 2001; 103:2717-2723.

24. Majors A, Ehrhart LA, Pezacka EH. Homocysteine as a risk factor for vascular disease. Enhanced collagen production and accumulation by smooth muscle cells. Arterioscler Thromb Vasc Biol. 1997 Oct;17(10):207481.

25. Welch GN, Loscalzo J. Homocysteine and atherothrombosis. N Engl J Med. 1998 Apr 9;338(15):1042-50.26. Nygård O, Nordrehaug JE, Refsum H, Ueland PM, Farstad M, Vollset SE. Plasma homocysteine levels and mortality in patients with coronary artery disease. N Engl J Med. 1997 Jul 24;337(4):230-6.

26. Homocysteine Studies Collaboration. Homocysteine and risk of ischemic heart disease and stroke: a metaanalysis. JAMA. 2002 Oct 23-30;288(16):2015-22.

27. Polidori MC, Savino K, Alunni G, Freddio M, Senin U, Sies H, Stahl W, Mecocci P. Plasma lipophilic antioxidants and malondialdehyde in congestive heart failure patients: relationship to disease severity. Free Radic Biol Med. 2002 Jan 15;32(2):148-52.

28. Polidori MC, Praticó D, Savino K, Rokach J, Stahl W, Mecocci P. Increased F2 isoprostane plasma levels in patients with congestive heart failure are correlated with antioxidant status and disease severity. J Card Fail. 2004 Aug;10(4):334-8.

29. Rexrode KM, Carey VJ, Hennekens CH, Walters EE, Colditz GA, Stampfer MJ, Willett WC, Manson JE. Abdominal adiposity and coronary heart disease in women. JAMA. 1998 Dec 2;280(21):1843-8.

30. Testa G, Cacciatore F, Galizia G. Waist circumference but not body mass index predicts longterm mortality in elderly subjects with chronic cardiac failure. J Am Geriatr Soc. 2010; 58:1433-1440.

31. Hu G, Jousilahti P, Antikainen R, Katzmarzyk PT, Tuomilehto J. Joint effects of physical activity, body mass index, waist circumference, and waist-to-hip ratio on the risk of heart failure. Circulation. 2010 Jan 19;121(2):237-44. doi: 10.1161/CIRCULATIONAHA.109.887893. Epub 2010 Jan 4.

32. Starkebaum G, Harlan JM. Endothelial cell injury due to copper-catalyzed hydrogen peroxide generation from homocysteine. J Clin Invest. 1986 Apr;77(4):1370-6.

33. Agarwal A, Shen H, Agarwal S, Rao AV. Lycopene Content of Tomato Products: Its Stability, Bioavailability and In Vivo Antioxidant Properties. J Med Food. 2001 Spring;4(1):9-15.

34. Poland B, Frohlich K, Haines RJ, Mykhalovskiy E, Rock M, Sparks R. The social context of smoking: the next frontier in tobacco control? Tob Control. 2006 Feb;15(1):59-63.

35. Hadley CW, Clinton SK, Schwartz SJ. The consumption of processed tomato products enhances plasma

lycopene concentrations in association with a reduced lipoprotein sensitivity to oxidative damage. J Nutr. 2003 Mar; 133(3):727-32.

36. He J, Ogden LG, Bazzano LA, Vupputuri S, Loria C,Whelton PK. Dietary sodium intake and incidence of congestive cardiac failure in overweight us men and women: First National Health and Nutrition Examination Survey Epidemiologic Follow-up Study. Arch Intern Med. 2002 Jul 22;162(14):1619-24.

37. He J, Ogden LG, Vupputuri S, Bazzano LA, Loria $\mathrm{C}$, Whelton PK. Dietary sodium intake and subsequent risk of cardiovascular disease in overweight adults. JAMA. 1999 Dec 1;282(21):2027-34.

38. Bentley B, De Jong MJ, Moser DK, Peden AR. Factors related to nonadherence to low sodium diet recommendations in heart failure patients. Eur $\mathbf{J}$ Cardiovasc Nurs. 2005 Dec;4(4):331-6. Epub 2005 Jun 2 .

\section{How to cite this article?}

Chauhan AP, Shah PK. Impact of Lycopene intervention on serum homocysteine in patients of Myocardial Infarction. Int J Med Res Rev 2015;3(11):1327-1332. doi: 10.17511/ijmrr.2015.i11.241. 